Relato de Caso

\title{
Estimativa de tempo de morte por meio da entomofauna cadavérica em cadáveres putrefeitos: relato de caso
}

\section{Estimated time of death through the cadaveric entomofauna in decomposing cadavers: a case report}

\author{
Adelino Poli Neto', Erika C. Carvalho', Maria Luiza Cavallari ${ }^{1}$, Vitor A. P. \\ Gianvecchio', José Salomão Neto², Marco Antônio Tartarella², \\ Cristina Kanamura ${ }^{3}$, Daniel Romero Muñoz ${ }^{1}$
}

\begin{abstract}
Neto AP, Carvalo EC, Cavallari ML, Gianvecchio VAP, Neto JS, Tartarella MA, Kanamura C, Muñoz DR. Estimativa de tempo de morte por meio da entomofauna cadavérica em cadáveres putrefeitos: Relato de Caso. Saúde, Ética \& Justiça. 2009; 14(2):92-96.

Resumo: Relato do caso de uma senhora de sessenta e nove anos encontrada morta em sua residência, já em estado de putrefação, no qual a análise dos fenômenos cadavéricos foi imprecisa para determinar a cronotanatognose (de dois dias a algumas semanas). Foi, então, realizado o estudo da entomofauna cadavérica para determinar o PMI (post morten interval) e concluiu-se que a morte havia ocorrido oito dias antes.
\end{abstract}

Descritores: Entomologia; Cadáver; Medicina legal/métodos.

INTRODUÇÃO

A estimativa do tempo de morte do cadáver, ou cronotanatognose, tem grande importância para a justiça, tanto na esfera penal quanto na cível. Nas investigações policiais, o conhecimento da hora da morte é fundamental para saber por onde andou e com quem a vítima poderia ter estado antes de morrer. Em varas de sucessão no foro cível, quando há mais de um falecimento, é necessário estabelecer quem morreu primeiro para determinar quem tem direito a herança.

$\mathrm{Na}$ prática pericial, a determinação da hora da morte é realizada por meio da análise dos fenômenos cadavéricos. Nota-se, porém, na literatura médico-legal, uma grande variabilidade quanto ao tempo de aparecimento destes fenômenos no cadáver. Além disso, os fenômenos cadavéricos podem sofrer influência de fatores

\footnotetext{
1 Laboratório de Zoologia Médico-Legal, Instituto Oscar Freire, Departamento de Medicina Legal, Ética Médica, Medicina Social e do Trabalho da Faculdade de Medicina da Universidade de São Paulo, São Paulo, Brasil

2 Instituto Médico Legal da Zona Oeste, São Paulo, Brasil

3 Divisão de Patologia, Instituto Adolfo Lutz, São Paulo, Brasil

ENDEREÇO PARA CORRESPONDÊNCIA: Laboratório de Zoologia Médico-Legal, Instituto Oscar Freire, FMUSP. Av. Dr. Arnaldo, 455. CEP 01246-903, São Paulo, SP. E-mail: entomologia_iof@ hotmail.com
} 
Neto AP et al. Estimativa de tempo de morte

externos, como temperatura do ambiente, roupas, local do óbito, e de fatores intrínsecos, como idade, compleição física, causa da morte, etc. Desta maneira, a avaliação da hora em que ocorreu o óbito utilizando apenas a análise destes fenômenos é impossível de ser realizada de forma exata com segurança. Portanto, o intervalo post mortem é habitualmente avaliado em faixas de tempo.

Em cadáveres putrefeitos, esta avaliação é ainda mais imprecisa, quase sempre estimada em faixas de dias a semanas, e é realizada com menor margem de segurança. Nesses casos, o método que pode ser utilizado para a determinação do PMI (post morten interval) com maior precisão e segurança é o estudo da entomofauna cadavérica.

A Entomologia Forense é a ciência que estuda os insetos, ácaros, aranhas, borboletas e mariposas, formigas e outros artrópodes com a finalidade de auxiliar a justiça. Além da aplicação na determinação do PMI, esse tipo de estudo permite verificar se ocorreu translado do corpo entre regiões urbana e rural, se houve ataque por animais silvestres, no caso de ambientes abertos, ou se o cadáver foi encontrado em ambientes fechados. A estimativa do PMI por meio da entomologia forense baseia-se na comparação de dados sobre o desenvolvimento de insetos, do ovo até a fase adulta, obtidos em análises laboratoriais de material coletado no corpo ou próximo deste quando da sua descoberta, seja ele ovos, larvas, pupas, pupários ou insetos adultos.

\section{DESCRIÇÃo}

Mulher de sessenta e nove anos, viúva, foi encontrada em óbito no interior de residência de alvenaria, vestida com blusa e calça do mesmo tecido tipo pijama e corpo coberto com cobertor, já com sinais de putrefação, sendo então encaminhada como morte suspeita ao Instituto Médico Legal (IML) - Equipe de Perícias Médico Legais - Oeste, para exame de corpo de delito (exame necroscópico).

No exame necroscópico, observaram-se os seguintes fenômenos transformativos destrutivos: mancha verde no corpo todo, cadáver de aspecto gigantesco e deformado, exoftalmia, protrusão da língua e dos órgãos genitais, enfisema subcutâneo, flictenas, destacamento da epiderme e circulação póstuma de Brouardel. Notou-se também a presença de ovos e larvas de animais necrofágos e não havia lesões externas traumáticas.

No exame interno verificou-se que o encéfalo estava se liquefazendo, as vísceras torácicas e abdominais encontravam-se todas amolecidas, não havia lesões traumáticas e o exame do coração revelou artérias coronárias endurecidas com estreitamento da luz. Concluiu-se que se tratava de uma morte de causa natural, de provável etiologia cardíaca.

Antes do exame necroscópico, foram coletados ovos na região lateral esquerda do pescoço, que se encontrava ligeiramente flexionado, formando dobras na pele, mantendo o local úmido e escuro, sendo propício para a instalação dos ovos de insetos. Nas vestes da vítima, após minuciosa procura, foram encontradas larvas de terceiro instar para fase de pré-pupa. Os ovos e as larvas foram coletados com pincel e pinça, respectivamente, os ovos foram colocados em placas de Petri com papel de filtro umedecido e as larvas em frascos plásticos, e levados para o Laboratório para serem criados até alcançarem a fase adulta.

Parte das larvas colhidas foram sacrificadas em laboratório com água a $70^{\circ} \mathrm{C}$ para serem pesadas, medidas, e avaliadas quanto à sua fase de desenvolvimento pós período embrionário (3o instar); para desenvolvimento das larvas, foi utilizado viveiro de material plástico, preparado com aproximadamente 10 centímetros de espessura de terra para pupação e coberto com tecido tipo voal. Os ovos eclodidos em 8 horas no laboratório transformaram-se em larvas de 10 instar (fase) e foram alimentados com carne bovina moída em uma proporção de $1 \mathrm{~g}$ por larva. Com média de peso de $0.0052 \mathrm{~g}$ e comprimento de $0,6 \mathrm{~cm}$, após ecdise, transformaram-se em larvas de segundo instar, pesando em média $0,0275 \mathrm{~g}$ e com comprimento de 1,2 cm; depois da última ecdise, a larva de terceiro instar pesava 0,0321 g e media 1,25 cm. Em seguida, houve a pupação e a transformação em imagos, que foram colhidos e classificados como sendo Muscina stabulans. Essa mosca é semelhante à mosca doméstica, mas um pouco mais robusta. Os adultos entram nos domicílios. As formas imaturas se desenvolvem em fezes humanas e de outros animais, alimentos, frutas em decomposição, cadáveres 
humanos, carcaças animais, etc. É relacionada com miíase humana.

Algumas larvas foram separadas para processamento Anátomo Patológico, técnica histológica, isto é, desidratação em álcool, diafanização em xilol, e preparo em embebimento em parafina. Esta fase foi processada em equipamento programado para levar o material a vários banhos seqüenciais de álcool absoluto $(5 x)$, xilol $(5 x)$ e parafina $(2 x)$. Após o banho de parafina, o material foi retirado do equipamento e incluído em bloco de parafina por meio de um molde apropriado para este fim. Nesta fase do processo, o material deve ser colocado com atenção quanto ao sentido de orientação, para que sejam obtidos cortes dos espiráculos posteriores, que são a estrutura de interesse para fins de classificação (fendas espiraculares), estando voltado para o fundo do molde. O bloco foi então submetido a resfriamento (no freezer) para facilitar o processo de corte em micrótomo rotativo. A partir daqui foram obtidos cortes seriados (3 micrômeros cada) do material, que foram fixados em lâminas para microscopia que, por sua vez, foram levadas à estufa a $60^{\circ} \mathrm{C}$ por uma hora para desparafinização.

O método de coloração empregado no material foi o hematoxilina-eosina (Hematoxilina de Harris/ Eosina amarela): desparafinização completa em xilol (2x); rehidratação em banhos de álcoois: absoluto (3x), 95\% (1x), 80\% (1x); lavagem em água corrente e destilada; banho em corante Hematoxilina de Harris (1 minuto) - lavagem em água corrente destilada; banho em álcool 95\% (3x); banho em corante Eosina amarela (30 segundos); desidratação em banhos em álcool 95\% (3x) e álcool absoluto (4x) e montagem com Entellan (resina sintética para microscopia) em lamínula, utilizando-se microscópio óptico nos aumentos de 100x e 400x.

Os insetos adultos foram sacrificados em câmara mortuária contendo acetato de etila e posteriormente colocados por 12 horas em líquido fixador de Dietrich. Esses insetos também foram inoculados com seringa $e$ agulha (comumente utilizadas para aplicação de insulina) entre o tórax e o abdome, foram classificados taxonomicamente, alfinetados e colocados em gavetas entomológicas, que se encontram no Laboratório de Zoologia Médico Legal do Instituto Oscar Freire.

\section{Discussão e Conclusão}

A putrefação cadavérica é o processo de decomposição da matéria orgânica por bactérias e pela fauna macroscópica. Os fenômenos putrefativos seguem determinada evolução cronológica, mas, sem uma precisão rigorosa, é possível encontrar em cadáveres a simultaneidade de vários períodos transformativos. Classicamente, a putrefação se desenvolve em quatro fases ou períodos distintos: período de coloração, período gasoso, período coliquativo e período de esqueletização.

O período de coloração, ou fase cromática da putrefação, tem como principal característica o aparecimento da mancha verde, que se inicia comumente na fossa ilíaca direita devido à proximidade do ceco à pele, difundindo-se posteriormente para o abdômen, tórax, cabeça e membros. A coloração verde dos tegumentos é explicada pela produção de hidrogênio sulfurado ou gás sulfídrico produzidos pelas bactérias que se combinam com a hemoglobina, formando a sulfometahemoglobina, que possui colorido verde. O aparecimento da mancha verde, segundo Fávero, ocorre em torno de 18 a 22 horas após a morte, recobrindo totalmente o cadáver entre 07 a 12 dias; segundo França, em nosso meio, geralmente surge entre 20 e 24 horas após o falecimento. De acordo com Abreu, ${ }^{1}$ o clima influencia este tempo de aparecimento, assim, em ambiente moderadamente quente, surge no fim de 24 horas, em ambiente quente, entre 15 e 18 horas e, em ambiente frio, entre 4 a 5 dias .

No período gasoso há um aumento progressivo e rápido da produção de gases pelas bactérias, que se disseminam por todos os tecidos dando origem a um enfisema subcutâneo. Em conseqüência desse acúmulo de gases, o corpo vai ficando com aspecto gigantesco, com os olhos e língua proeminentes. Além disso, devido à pressão dos gases putrefativos no interior do cadáver, o sangue é propelido dos grandes vasos sanguíneos e do coração para a circulação periférica, deixando estes vasos bem visíveis com aspecto bastante característico, 
Neto AP et al. Estimativa de tempo de morte

sinal conhecido como circulação póstuma de Brouardel. Ainda nesta fase, a grande produção de líquidos, que migram para a superfície dá origem a bolhas (flictenas putrefativas) de tamanhos variados, nos tegumentos, local aonde a epiderme vai se destacando deixando a derme exposta; este período inicia-se por volta de dois dias após a morte, atingindo o máximo antes de uma semana e pode durar de uma a três semanas, de acordo com Hércules; já segundo Fávero, o início ocorre no prazo de uma a três semanas.

No caso em tela, o cadáver apresentava, dentre os fenômenos transformativos destrutivos, mancha verde no corpo todo, aspecto gigantesco e deformado, exoftalmia, protrusão da língua e dos órgãos genitais, enfisema subcutâneo, flictenas, destacamento da epiderme e circulação póstuma de Brouardel, portanto, encontrava-se no período gasoso da putrefação. Desta maneira, de acordo com a literatura médico legal, o PMI poderia ser estimado de dois dias a algumas semanas.

É importante citar que o fato do corpo estar coberto dificultou a postura de ovos em outro local, senão as partes descobertas (pescoço e cabeça). Após análise entomológica (próprio corpo e suas vestes), observou-se que havia presença de larvas de terceiro instar para pré-pupa nas roupas, abandonando o corpo para tentar pupar definitivamente e transformarem-se em adultos.

A análise histológica com coloração HE do espiráculo posterior das larvas e a criação em laboratório dos espécimes demonstrou que, após classificação taxonômica, chegou-se à conclusão de que o animal pertencia ao Filo Arthropoda; Classe Insecta; Ordem Diptera; Subordem
Brachycera; Família Muscidae; Gênero Muscina e Espécie M. stabulans

Em geral, o ciclo de vida em fase larval até pupa de um Díptero, Muscidae, (Holometábulo) passa por três instares (fases) cujos tempos de transformação variam de acordo com as espécies. A M.stabulans deposita cerca de 150 ovos sobre o substrato. A eclosão do ovo para larva de primeiro instar (L1) ocorre num período de aproximadamente de 8 a 12 horas dependendo da temperatura, umidade e situação sazonal, além de fatores intrínsecos e localização do substrato. O desenvolvimento da larva de primeiro a terceiro instar varia em até 9 dias para transformação em pupa.

Portanto, de acordo com GHA (Grau Hora Acumulado) e GDA (Grau Dia Acumulado) seu PMI foi estimado em 8 (oito) dias. Isto demonstra a importância da Entomologia Forense no estabelecimento do PMI, por permitir uma precisão maior do que a dos estudos dos fenômenos cadavéricos. Com a análise da entomologia, quanto maior o tempo de morte, maior a precisão do PMI .Finalmente, o encontro apenas desta espécie (M.stabulans) também demonstra que o cadáver não foi translocado, pois este inseto tem como característica alto índice de sinantropia, além dos hábitos domésticos. Esse tipo de informação pode ser considerado como mais uma contribuição do estudo entomológico para a atividade forense.

Agradecimento a José Benedito de Oliveira Auxiliar de necropsia.

Neto AP, Carvalo EC, Cavallari ML, Gianvecchio VAP, Neto JS, Tartarella MA, Kanamura C, Muñoz DR. Estimated time of death through the cadaveric entomofauna in decomposing cadavers: Case Report. Saúde, Ética \& Justiça. 2009;14(2):92-96.

ABSTRACT: This study reports a case of a sixty-nine years old lady who was found dead in her house, in state of putrefaction. The study of cadaveric phenomena was imprecise and determined the post mortem time as two weeks and some days. The entomofauna analysis resulted to be a more accurate cronotanatognosis method, showing that the death had occurred exactly eight days before the body was found.

KEY WORDS: Entomology; Cadaver; Forensic medicine/methods. 
1. Abreu HT. Manual de necropsia forense. $2 a$ ed. Rio de Janeiro: Livraria Quaresma; 1930

2. Benecke M. A brief history of forensic entomology. Forensic Sci Int. 2001.

3. Catts EP, Goff ML. Forensic entomology in criminal investigations. Ann Rev Entomol. 1992.

4. Costa C, Ide S, Simonka CE. Insectos Inmaduros Metamorfosis e Identificación. Zaragoza: Monografias Tercer Milênio; 2006.

5. Donald J, Borror, Dwight M. DeLong Introdução ao estudo dos insetos. São Paulo: Edusp; 1969.

6. Hall MJR. Best practice in forensic entomology - standarts and guidelines. Int $\mathrm{J}$ Legal Med. 2007.

7. Oliveira-Costa J. Entomologia forense, quando os insetos são vestígios. Campinas: Millenium; 2007.

8. Marcondes CB, Entomologia médica e veterinária. São Paulo: Atheneu; 2001.

Recebido em: 18/08/09

Aprovado em: 31/08/09 